RELACult - Revista Latino-Americana de Estudos em Cultura e Sociedade e-ISSN 2016/Atual: 2525-7870 | e-ISSN 2015/2016: 2447-018X

\title{
Reflexões sobre Comportamentos Alimentares de Universitários Estrangeiros em Foz Do Iguaçu-PR
}

\author{
Reflexiones sobre Comportamientos Alimentarios de Universitarios
}

\author{
Extranjeros en Foz De Iguaçu-PR
}

Reflections on Food Behavior of Foreign Students in Foz Do Iguaçu-PR

Paola Stefanutti ${ }^{1}$

Marcela Sobreira Sepúlveda Almendra

Gislaine Silveira Simões ${ }^{3}$

Paula Marasca Oro ${ }^{4}$

\begin{abstract}
Resumo
Estudar fora do país de origem permite ao estudante estrangeiro vivenciar novos desafios inerentes à vida universitária, inclusive adaptar-se a uma nova alimentação com base nos ingredientes disponíveis. Este estudo teve como objetivo realizar reflexões sobre o comportamento alimentar de universitários estrangeiros da Universidade Federal da Integração Latino Americana (UNILA). Foi utilizada metodologia quantitativa, por meio de questionário bilíngue aplicado a universitários voluntários da referida universidade. Com a aplicação do questionário realizou-se uma discussão baseando-se nos itens tempo, dinheiro, conhecimento culinário e nutricional, alimentos consumidos e padrão de compras de alimentos. Acrescentou-se ainda um diálogo sobre as adaptações alimentares dos universitários e suas dificuldades, reforçando o alimento com um fator identitário. Espera-se que esta pesquisa possa contribuir para outras análises, promovendo uma aproximação entre nutrição e ciências sociais, entendendo a alimentação como um fenômeno social a ser analisado de forma interdisciplinar.
\end{abstract}

Palavras-Chave: alimentação saudável; América-latina; universitários.

\section{Resumen}

Estudiar fuera del país de origen permite al estudiante extranjero experimentar nuevos desafíos inherentes a la vida universitaria, incluso adaptarse a una nueva alimentación basada en los ingredientes disponibles. Este estudio tuvo como objetivo realizar reflexiones sobre el comportamiento alimentario de universitarios extranjeros de la Universidade Federal da Integração Latino Americana (UNILA). Se utilizó metodología cuantitativa, por medio de cuestionario bilingüe aplicado a universitarios voluntarios de dicha universidad. Con la aplicación del cuestionario se realizó una discusión basándose en los ítems tiempo, dinero, conocimiento culinario y nutricional, alimentos consumidos y patrón de compras de alimentos. Se añadió un diálogo sobre las adaptaciones

\footnotetext{
${ }^{1}$ Mestre em Sociedade, Cultura e Fronteiras; Universidade Estadual do Oeste do Paraná - UNIOESTE; Foz do Iguaçu, Paraná, Brasil; paola.stefanutti@ifpr.edu.br

${ }^{2}$ Bacharel em Direito; Instituto Federal do Paraná - IFPR; Foz do Iguaçu, Paraná, Brasil; marcelaalmendra@gmail.com

${ }^{3}$ Doutora em Ciência de Alimentos; Instituto Federal do Paraná - IFPR; Foz do Iguaçu, Paraná, Brasil; gislaine.simoes@ifpr.edu.br

${ }^{4}$ Mestrado em Tecnologia de Alimentos; Instituto Federal do Paraná - IFPR; Foz do Iguaçu, Paraná, Brasil; paula.oro@ifpr.edu.br
} 
alimentarias de los universitarios y sus dificultades, reforzando el alimento con un factor identitario. Se espera que esta investigación pueda contribuir a otros análisis, promoviendo una aproximación entre nutrición y ciencias sociales, entendiendo la alimentación como un fenómeno social a ser analizado de forma interdisciplinaria.

Palabras claves: alimentación sana; América Latina; universitários.

\section{Abstract}

Studying outside of origin country allows the foreign student to experience new challenges inherent in university life, including adapting to new food based on the available ingredients. The objective of this research was to reflections on the food behavior of foreign university students from the Universidade Federal da Integração Latino Americana (UNILA). It was used the qualitative methodology, through a bilingual questionnaire applied to students volunteers from this university. With the application of the questionnaire, a discussion was held based on the items time, money, culinary and nutritional knowledge, food consumed and standard food purchases. A dialogue was also added on the food adaptations of the foreign students and their difficulties, reinforcing the food with an identity factor. It is hoped that this research may contribute to other analyzes, promoting an approximation between nutrition and social sciences, understanding food as a social phenomenon to be analyzed in an interdisciplinary way.

Keywords: healthy eating; Latin America; students.

\section{Introdução}

A Universidade Federal da Integração Latino-americana (UNILA) situada no estado do Paraná, em Foz do Iguaçu, cidade fronteiriça à Argentina e ao Paraguai, criada pela Lei $n^{\circ}$ 12.189 de 12 de janeiro de 2010 é uma Universidade com especificidades que a tornam única dentro do cenário acadêmico brasileiro, uma vez que faz parte de um projeto político de integração e cooperação solidária cuja missão é: “[...]com base na indissociabilidade de ensino, pesquisa e extensão é formar sujeitos críticos e profissionais qualificados, aptos a contribuir com a integração, o desenvolvimento regional e o intercâmbio cultural, científico, tecnológico e educacional da América Latina e do Caribe"5 .

Desde o ano de sua fundação, ingressaram no corpo discente da UNILA 3056 estudantes de diversas nacionalidades. No primeiro semestre de 2016, adentraram na Universidade 1084 estudantes, sendo 790 brasileiros, 119 paraguaios e os demais 175 se dividiam em outras quinze nacionalidades ${ }^{6}$.

As características de cooperação e integração entre os povos, intrínsecas à missão institucional da Universidade, faz suscitar questões sobre a adaptação destes estudantes, especialmente no que diz respeito à alimentação, uma vez que estes vêm dos mais variados

\footnotetext{
${ }^{5}$ UNILA. Universidade da Integração Latino-Americana. A vocação da UNILA. Disponível em: <https://www.unila.edu.br/conteudo/voca\%C3\%A7\%C3\%A3o-da-unila> Acesso em: 13 de setembro de 2016.

${ }^{6}$ UNILA. Universidade da Integração Latino-Americana. Disponível em: UNILA em Números. <https://www.unila.edu.br/sites/default/files/files/unila-em-numeros.pdf> Acesso em: 26 de outubro de 2016.
} 
países e trazem consigo sua cultura alimentar, suas referências e histórias, seus comportamentos alimentares, ao mesmo tempo em que buscam adaptar-se ao seu novo modo de vida.

Os hábitos, comportamentos ou práticas alimentares de universitários são temas de inúmeros trabalhos acadêmicos, sendo constante objeto de análise. Porém, diferente de outros estudos dessa área no território nacional, tem-se universitários estrangeiros que em sua grande maioria chegaram recentemente à Foz do Iguaçu, e enfrentam as mesmas dificuldades e desafios da vida universitária, porém ainda se depararam com uma nova realidade alimentar, com ingredientes, produtos, costumes alimentares e infraestrutura diferentes ao seu país de origem.

Este artigo traz um diálogo entre as áreas de Ciências Sociais e Nutrição, focando não apenas o nutricional, mas compreendendo a alimentação como um campo interdisciplinar. Para tal, embasou-se no Guia alimentar para a população brasileira (BRASIL, 2014), lançado em 2014. Este Guia diferente de outros traz, em uma linguagem simplificada, uma série de orientações para uma alimentação adequada e saudável, porém levando em consideração as dimensões culturais, sociais e econômicas. Assim, não apresenta a "tradicional" pirâmide alimentar, mas divide os alimentos entre categorias que devem ser mais consumidas como os alimentos in natura ou minimamente processados, os alimentos processados e os alimentos ultraprocessados, sendo que esta última categoria deve ser evitada. O Guia ainda envolve questões como incentivo ao tempo para preparar os alimentos, valorização das habilidades culinárias, transmissão das comidas tradições, e a importância do ato de comer e a comensalidade.

Apesar do Guia ser destinado para a população brasileira, pode ser ampliado para outras nacionalidades, uma vez que suas discussões são universais. Neste contexto, o olhar para a alimentação transcende o foco da saúde e nutrição e compreende as práticas alimentares como valor simbólico e identitário.

Neste trabalho questionou-se a qualidade da alimentação destes universitários através de discussões sobre tempo, dinheiro, conhecimento culinário e nutricional, alimentos consumidos e padrão de compras de alimentos. Acrescenta-se ainda um diálogo sobre as adaptações alimentares e suas dificuldades.

\section{Metodologia}

Para levantamento dos dados foi aplicado um questionário bilíngüe, em português e espanhol, à universitários estrangeiros da UNILA. Sendo assim, utilizou-se uma metodologia quantitativa. O questionário foi anônimo e na primeira parte levantou-se dados pessoais como nacionalidade, gênero, idade, curso, período de estudo e tempo que reside na cidade de Foz do 

e-ISSN 2016/Atual: 2525-7870 | e-ISSN 2015/2016: 2447-018X

Iguaçu. A segunda parte do questionário era composto por dezesseis perguntas, sendo dez objetivas e seis discursivas, todas buscando investigar os comportamentos alimentares e a qualidade nutricional da dieta destes estudantes. Procurou-se identificar o número diário de refeições, alimentos mais consumidos, dificuldades para uma alimentação saudável, e ainda padrão de compra de alimentos e conhecimento culinário.

Para a aplicação do questionário foi realizada visita às moradias da referida Universidade, todas localizadas na cidade de Foz do Iguaçu. Após uma explanação acerca dos objetivos por parte dos pesquisadores, os estudantes voluntariamente se dispuseram a colaborar com a pesquisa. Com a coleta dos dados foi realizada a tabulação dos dados e análise de resultados obtidos, o que possibilitou a identificação do perfil dos estudantes. Com os resultados, buscou-se compreender a qualidade alimentar e seus comportamentos alimentares, considerando estes como reflexo de sua vida social, cultural e econômica, uma vez que estão imersos na cultura brasileira, convivendo com estudantes de diversas nacionalidades.

\section{Resultados e Discussões}

\subsection{Perfil dos Universitários}

A pesquisa contou com a participação de 33 universitários estrangeiros, e conforme apresentado na Figura 1, as nacionalidades contempladas foram: haitianos, colombianos, paraguaios, chilenos, equatorianos, venezuelanos, panamenhos, peruanos, salvadorenhos e cubanos. Sendo que a maior porcentagem foi de haitianos (21\%).

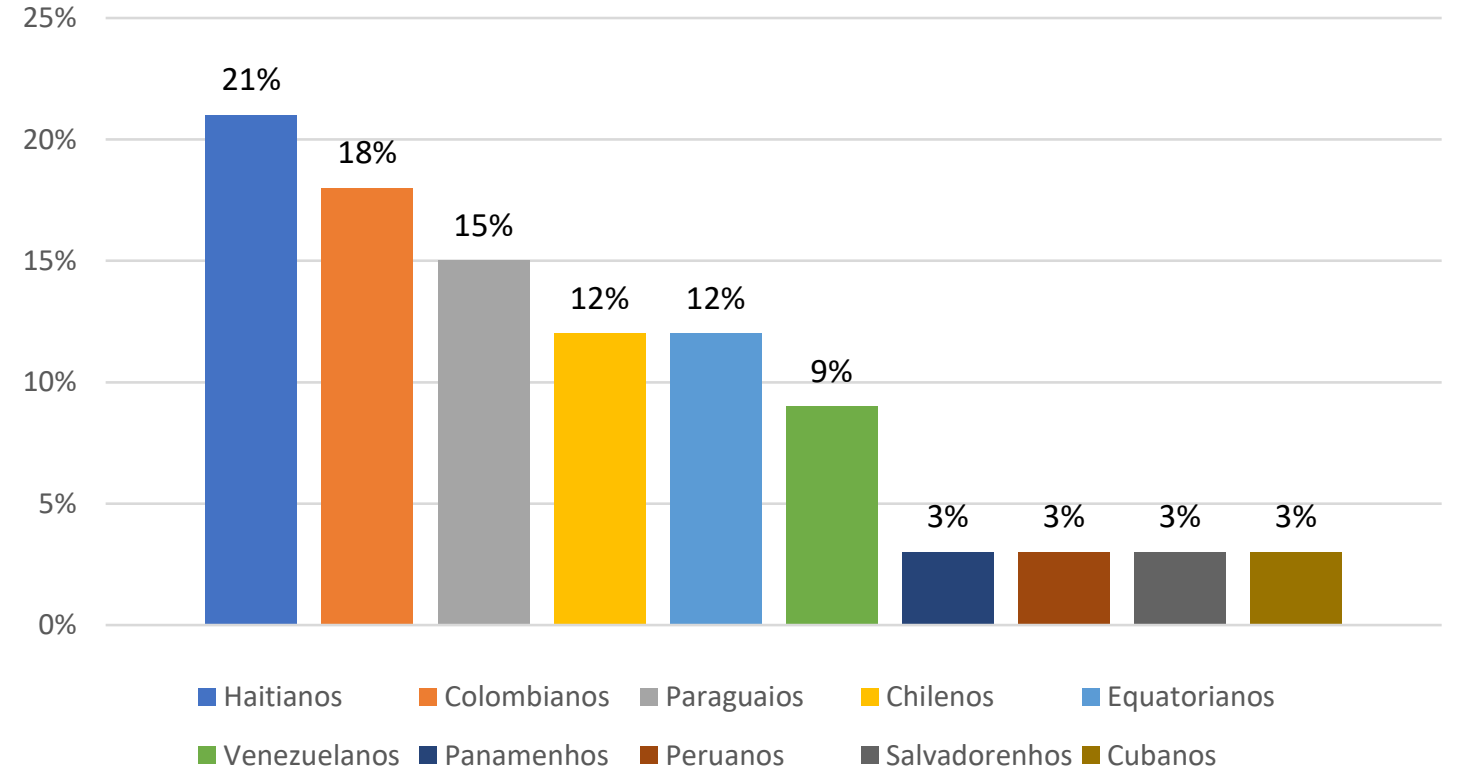

Figura 1: Porcentagens de entrevistados conforme nacionalidade. Fonte: do autor 
Entre os estudantes que responderam ao questionário, a maioria residia em Foz do Iguaçu há menos de um ano, sendo que $64 \%$ residia entre 5 a 6 meses, $18 \%$ entre 1 a 2 anos, $15 \%$ entre 2 a 3 anos e $3 \%$ estão há mais de três anos na cidade.

Dos questionários respondidos, $52 \%$ eram do gênero masculino, $42 \%$ do gênero feminino e $6 \%$ não responderam à pergunta. Sobre a faixa etária, constatou-se que $3 \%$ tinham 17 anos de idade, $52 \%$ entre 18 a 21 anos, 33\% entre 22 e 25 anos e $12 \%$ entre 26 a 27 anos. Com esses dados é possível verificar que grande parte dos estudantes que responderam ao questionário (85\%) compreendia a faixa etária entre 18 a 25 anos de idade, estando em consonância com os dados de 2014 do Censo da Educação Superior, realizado pelo Ministério da Educação através do Instituto Nacional de Estudos e Pesquisas Educacionais Anísio Teixeira (INEP), que revelou que a idade mediana dos estudantes matriculados nos cursos de graduação presenciais nas Instituições de Ensino Superior é de 21 anos de idade ${ }^{7}$.

Estes estudantes estavam matriculados em quinze cursos de seis diferentes áreas de conhecimento de acordo com a divisão da Coordenação de Aperfeiçoamento de Pessoal de Nível Superior (CAPES), sendo estas Ciências Sociais Aplicadas: Arquitetura e Urbanismo, Administração Pública e Políticas Públicas, Ciências Econômicas; Engenharias: Engenharia Química, Engenharia Civil, Engenharia Física, Engenharia de Energias Renováveis; Ciências Biológicas: Biotecnologia; Ciências da Saúde: Medicina; Ciências Humanas: Relações Internacionais, Antropologia e História; Ciências Linguística, Letras e Artes: Letras (Espanhol/Português) e Música. Foi possível contemplar, portanto, quinze dos trinta cursos de graduação oferecidos pela UNILA, e nove das dezessete nacionalidades presente na universidade, o que reflete a heterogeneidade abarcada pela pesquisa.

\subsection{Comportamentos Alimentares dos Universitários}

Com relação aos comportamentos alimentares, os universitários foram questionados sobre como poderiam melhorar sua alimentação, e citaram em uma resposta discursiva, diversos itens: possuir mais tempo, possuir mais dinheiro, aprender a cozinhar melhor, comer frutas e verduras, ter horário de alimentação adequada, possuir conhecimento de uma dieta equilibrada e aprender a fazer compras. As porcentagens de respostas obtidas para cada item estão

\footnotetext{
${ }^{7}$ Ver mais em:

<http://download.inep.gov.br/educacao_superior/censo_superior/documentos/2015/notas_sobre_o_censo_da_ed ucacao_superior_2014.pdf>.
} 

e-ISSN 2016/Atual: 2525-7870 | e-ISSN 2015/2016: 2447-018X

apresentadas na Figura 2. Sendo que possuir tempo e possuir dinheiro foram os itens mais citados pelos entrevistados. Diante destes resultados, foram realizadas discussões sobre cada um desses itens.

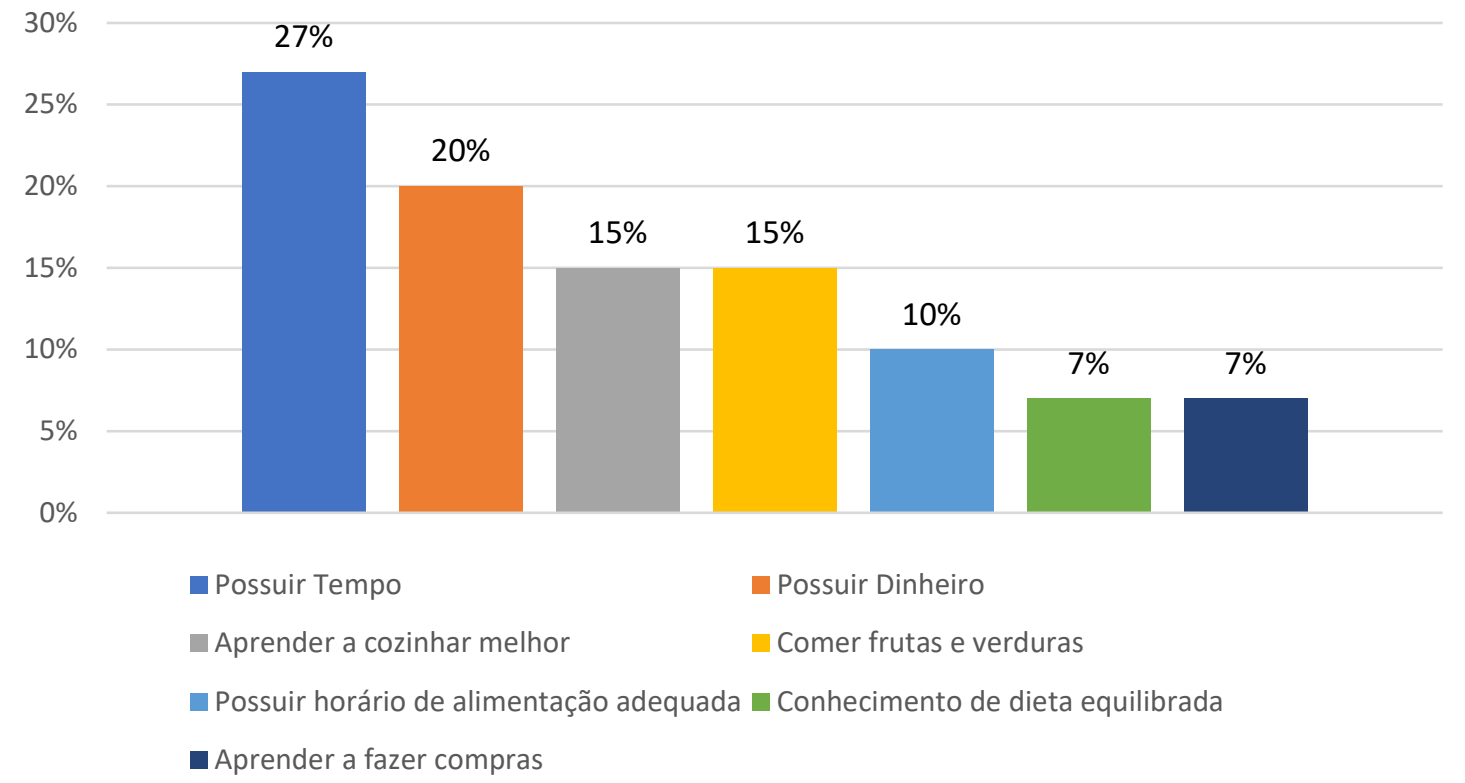

Figura 2 - Porcentagens de respostas sobre como melhorar a alimentação. Fonte: do autor

Um dos "vilões" para a obtenção de uma alimentação saudável segundo o Guia alimentar para a população brasileira (BRASIL, 2014), é o tempo, ou melhor, a falta dele. Por isso no Guia entre os dez passos para uma alimentação adequada e saudável consta a organização do tempo para a compra, o preparo e a realização do ato de comer. Nesta perspectiva foram questionados se os estudantes possuíam tempo para o preparo de uma alimentação saudável, sendo que $70 \%$ responderam que não possuíam e $30 \%$ que possuíam.

A questão da falta de tempo para obterem uma alimentação nutricionalmente balanceada, pode estar associada ao período de estudo destes estudantes. Pois $12 \%$ dos universitários estudavam em 1 (um) turno do dia, 24\% em 2 (dois) turnos, 55\% em 3 (três) turnos, $9 \%$ não responderam à pergunta. A distância entre as moradias e os dois campi da Universidade é de $15 \mathrm{~km}$, porém o único meio de transporte dos entrevistados é o transporte coletivo, o que inviabilizava o retorno para a moradia, entre um turno e outro, restringindo ainda mais o tempo livre dos estudantes.

Aproveitando a questão do tempo discute-se a problematização de possuir horário de alimentação adequada, pois $10 \%$ afirmaram a falta do mesmo. Dentre essa perspectiva das refeições diárias, $39 \%$ dos estudantes declararam tomar o café da manhã, $18 \%$ o lanche de 
manhã, 97\% realizavam o almoço, 30\% o lanche da tarde e $61 \%$ jantavam. Portanto, o almoço pode ser considerado a refeição mais importante destes estudantes, sendo que quase todos afirmaram que o consomem, seguido do jantar e depois do café da manhã.

Os comportamentos alimentares envolvem uma série de práticas à mesa e em torno da alimentação, assim como a própria refeição. O sociólogo brasileiro Renato Ortiz discute sobre a padronização alimentar e sobre a redefinição do significado da refeição.

Contrariamente à refeição tradicional, que se fazia em horários fixos, come-se agora em horas variadas [...] Se antes os membros da família se sentavam regularmente à mesa, partilhando um momento em comum, hoje, cada um tende a coordenar seu tempo em função de suas próprias atividades (ORTIZ, 2003, p. 85).

Porém, independente de seus significados sociais e culturais, foi expressivo a quantidade de refeições que os estudantes afirmaram fazer, pois verifica-se que $18 \%$ disseram fazer uma refeição por dia, $27 \%$ duas refeições, $45 \%$ três refeições por dia, $9 \%$ quatro refeições por dia e não há nenhum estudante que declarou fazer cinco refeições diárias.

Para a obtenção de uma alimentação saudável e nutricionalmente balanceada, segundo recomendações de Sichieri et al. (2000), um adulto deve além de outras questões, fazer quatro refeições ao dia. Constata-se, portanto, que $91 \%$ dos estudantes declararam fazer menos refeições do que o recomendado. Assim, essa forma de estruturação da realização das refeições pode significar adaptações às necessidades, seja pela questão financeira ou de tempo.

Nota-se que há uma alta carga horária de estudo, elemento que, ao ser confrontado com o número de refeições diárias consumidas pelos estudantes, confirmou a questão do tempo como principal ponto desfavorável para a obtenção de uma alimentação mais adequada.

A questão econômica foi o segundo maior aspecto apontado pelos estudantes (citado por $20 \%$ dos entrevistados), que influenciava diretamente na escolha por produtos, ingredientes, marcas e, por fim, nos comportamentos alimentares. Luce Giard, historiadora francesa, uma das autoras de "A Invenção do Cotidiano", discute sobre como o aspecto econômico influencia nos comportamentos alimentares e diz que: “[...] a prosperidade de uma família se traduzia antes de tudo por seu regime alimentar" (GIARD, 2008, p. 213). Portanto a prosperidade de uma família é expressa de uma maneira singular na mesa de cada residência, e no caso destes universitários também. A ideia de prosperidade à mesa, também está diretamente associada com a alimentação saudável, pois faz parte do senso comum o credo de que uma alimentação saudável e nutricionalmente equilibrada é necessariamente mais cara do que a alimentação não saudável. 
Embora legumes, verduras e frutas possam ter preço superior ao de alguns alimentos ultraprocessados, o custo total de uma alimentação baseada em alimentos in natura ou minimamente processados ainda é menor no Brasil do que o custo de uma alimentação baseada em alimentos ultraprocessados (BRASIL, 2014, p.110, grifo nosso)

Assim, adquirir hábitos como comprar produtos sazonais, pois estes sempre terão menor preço e em locais com menos intermediários, como é o caso das feiras, se torna uma alternativa para a obtenção de uma alimentação adequada e saudável sem necessidade de aumento de custos.

O terceiro maior item citado foi aprender a cozinhar melhor (citado por $15 \%$ dos entrevistados). Segundo o Guia alimentar para a população brasileira, no Brasil assim como em outros países, o processo de transmissão entre gerações das habilidades culinárias está em declínio, tendo como consequência disso, que os jovens possuem cada vez menos confiança e autonomia para cozinhar. Dentre os motivos cita-se:

[...] a desvalorização do ato de preparar, combinar e cozinhar alimentos como prática cultural e social, a multiplicação das tarefas cotidianas e a incorporação da mulher no mercado formal de trabalho, além da oferta massiva e da publicidade agressiva dos alimentos ultraprocessados. (BRASIL, 2014, p.112-113)

A perspectiva sobre a importância do ato de cozinhar, vem pautada nas discussões de Michael Pollan no livro Cozinhar: Uma História Natural da Transformação, em que o autor se dedica aos aspectos físicos, químicos, biológicos, sociais e culturais do ato. Para Pollan (2014 p.19), o cozinhar ensina sobre a: “[...] natureza do trabalho, o significado de saúde, sobre tradições e rituais, autoconfiança e comunidade, sobre os ritmos da vida cotidiana e a suprema satisfação de produzir algo que antes só conseguia me ver consumindo". O autor ainda evidencia que cozinhar envolve toda uma rede de relacionamentos sociais e ecológicos, e que o cozinhar faz com que se estabeleçam conexões, entre plantas, animais, solo, território, e com pessoas, que vendem, que cozinham e que degustam, que comem, que ruminam.

Dentro desta abordagem questionou-se sobre o conhecimento das habilidades culinárias, isto é, se os estudantes sabiam cozinhar ou tinham dificuldades para exercer esta atividade. Para Pollan (2014, p.29, grifo nosso): “O ato de cozinhar tem o poder de transformar mais do que plantas e animais: ele também nos transforma, de meros consumidores em produtores", assim quem cozinha faz parte do processo, está conectado a uma rede complexa maior que a própria atividade em si. Dos entrevistados $94 \%$ declararam saber cozinhar e $6 \%$ declararam não saber. Entretanto, dos que sabiam cozinhar, 70\% declararam saber cozinhar antes de sair de casa e 

e-ISSN 2016/Atual: 2525-7870 | e-ISSN 2015/2016: 2447-018X

$30 \%$ não sabiam cozinhar antes sair de casa. Estes dados apontam que os estudantes tiveram que se adaptar à nova realidade vivenciada, e aprenderam a cozinhar suas próprias refeições.

O próximo item citado para melhorar a alimentação foi sobre comer mais frutas e verduras (citado por 15\% dos entrevistados). Para esta discussão faz-se um paralelo com outro questionamento sobre os alimentos que compõem a alimentação diária destes estudantes, sendo que cada entrevistado poderia escolher uma ou mais opções de produtos. Os alimentos citados foram: arroz, pão, frutas, macarrão, verduras, fast food, carne, frango, outros, milho e com foram citados peixe, ovos, feijão e trigo. A Figura 3 apresenta as porcentagens de respostas para cada alimento citado nas entrevistas.

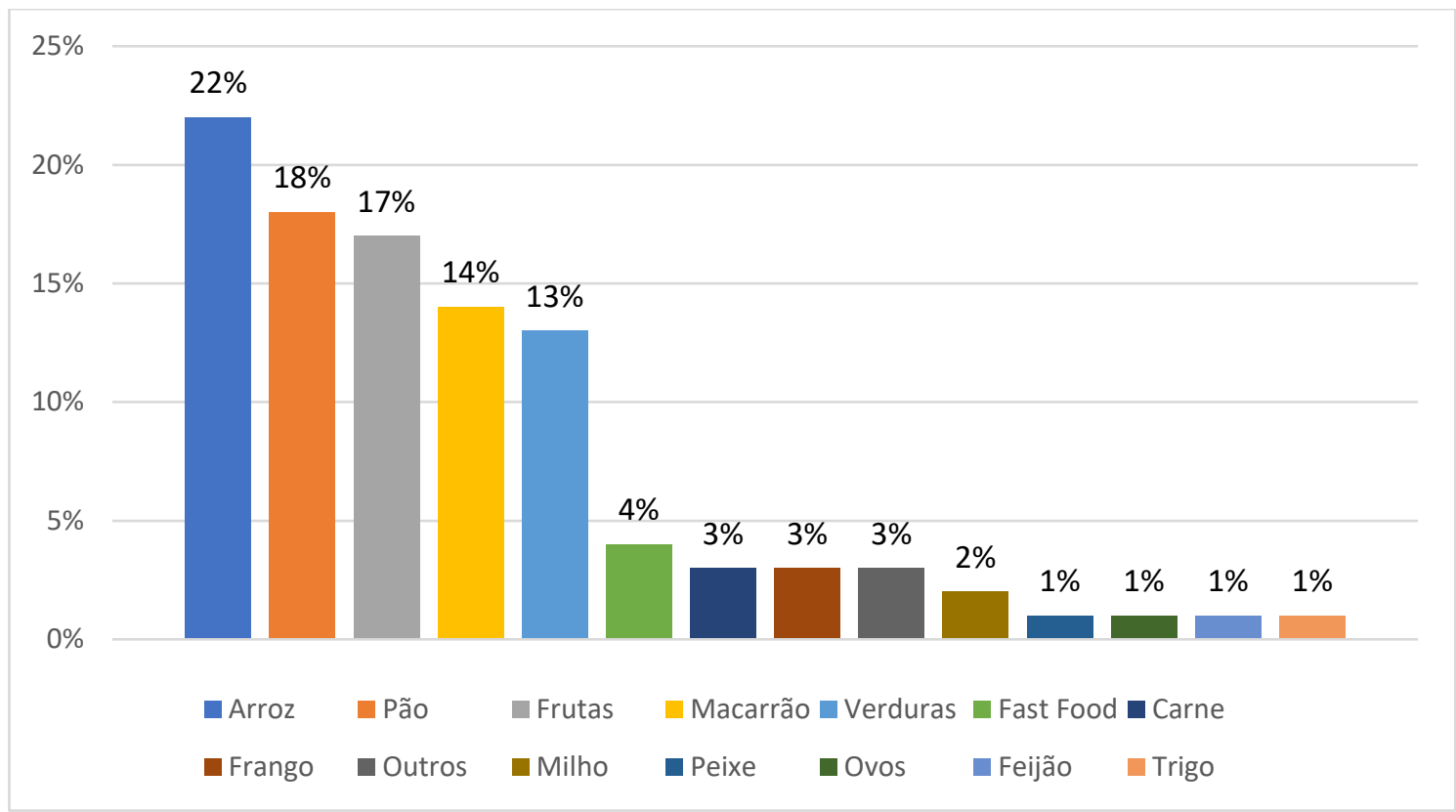

Figura 3 - Porcentagens de respostas para cada alimento citado pelos entrevistados. Fonte: do autor

Nesta perspectiva, percebe-se que o grupo dos carboidratos é o mais consumido, sendo, portanto, a base da alimentação dos estudantes, seguido nas frutas e verduras. Pode-se verificar o pouco consumo de proteínas de origem animal, apesar de nenhum dos estudantes ter se declarado vegetariano. Assim, ao conflitarmos o número de refeições consumidas e os alimentos que fazem parte da dieta dos estudantes, pode-se verificar que tanto no âmbito quantitativo quanto qualitativo há um quadro de vulnerabilidade alimentar destes jovens.

Porém se levarmos em consideração a classificação do Guia alimentar para a população brasileira (BRASIL, 2014) entre as categorias de alimentos têm-se os alimentos in natura ou minimamente processados, que devem ser a base da alimentação, os alimentos processados que deve ser limitado o consumo e alimentos ultraprocessados, que não devem ser consumidos. 

e-ISSN 2016/Atual: 2525-7870 | e-ISSN 2015/2016: 2447-018X

Portanto verifica-se que dentre os alimentos que os estudantes afirmaram comer diariamente estão em sua maioria, na categoria dos alimentos in natura ou minimamente processados, sendo estes: arroz, macarrão, frutas, verduras, peixe, ovos, feijão, trigo, carne, frango e milho. Dos alimentos processados há somente o pão e dos alimentos ultraprocessados foi citado o fast food. Foram desconsiderados o item outros.

O próximo item mencionado foi sobre ter conhecimento de uma dieta equilibrada, sendo que 7\% dos estudantes mencionaram este item. Isto demonstra claramente a importância da educação alimentar e nutricional, sendo que esta prática deveria ser incluída e instituída no currículo das escolas e universidades. A educação alimentar e nutricional proporciona a possibilidade para que as pessoas “[...] adotem práticas alimentares promotoras da saúde e para que compreendam os fatores determinantes dessas práticas, contribuindo para o fortalecimento dos sujeitos na busca de habilidades para tomar decisões e transformar a realidade" (BRASIL, 2014, p.22). Além de ter conhecimento do que comer, a educação traria a valorização do próprio ato de fazer e de comer.

O item aprender a fazer compras representou 7\% das respostas sobre o que poderiam melhorar para terem uma alimentação adequada. Ao serem questionados sobre o padrão de compra de alimentos, $100 \%$ dos estudantes afirmaram fazer suas compras em supermercados e somente $9 \%$ afirmaram que além de supermercados também compram em feiras, sendo que nenhum estudante declarou ter horta própria ou outros lugares para comprar seus produtos, tais como feiras de produtores locais. O Guia Alimentar para a população brasileira reforça a importância de fazer compras de alimentos em mercados, feiras ou varejão, pois favorece o aumento de produtos in natura ou minimamente processados, além de incentivar o desenvolvimento regional (BRASIL, 2014, p.107).

As feiras livres poderiam, inclusive, auxiliar no processo de adaptação e integração destes estudantes à cultura brasileira, pois além de serem locais de comercialização de produtores locais, refletem a cultura local, como é discutido por Guimarães (2010, p.7):

Ao mesmo tempo, o caráter comercial da feira livre mascara sua importância na manutenção e promoção da cultura popular. Ainda que imerso no discreto dia a dia desse evento, as noções de identidade, comunidade, hábitos, relações e comunicação aparecem fortemente durante toda a sua duração e possibilitam aos indivíduos em situação de subalternidade um sentimento de humanização.

Nesta mesma discussão da aquisição de compras, o Guia alimentar para a população brasileira ainda orienta sobre as compras coletivas e compra de alimentos orgânicos da agricultura de base agroecológica, contribuindo para o desenvolvimento da economia local, através da valorização do pequeno produtor (BRASIL, 2014, p.107-108). Entretanto, 58\% dos 
universitários afirmaram fazer as compras sozinhos e $42 \%$ declararam fazer em conjunto com outros estudantes. Uma hipótese levantada foi de que os estudantes que alegaram falta de recurso financeiro para uma dieta equilibrada nutricionalmente, seriam os mesmos que faziam suas compras sozinhos. Porém após o cruzamento dos dados e análise dos mesmos, verificouse que o fato de fazerem suas compras em conjunto não colaborou para melhorar a economia do estudante. Desses pontos, pode-se verificar ainda a própria dificuldade destes universitários realizarem as compras, o que será discutido no próximo tópico deste artigo.

\subsection{A Minha comida e a do Outro}

Um dos objetos de estudo desta pesquisa era em relação as adaptações dos universitários frente a alimentação em um novo território. Problematizando e consentindo com os antropólogos espanhóis da área da alimentação Jesús Contreras e Mabel Gracia, afirma-se que as cozinhas refletem as sociedades: "Cada grupo social possui um quadro de referências que guia a escolha de seus alimentos. Algumas dessas referências são compartilhadas com outros grupos, outras são exclusivas" (CONTRERAS \& GRACIA, 2011, p.139). Porém, essa afirmação não significa que os comportamentos alimentares se mantêm estáticos e não sofrem alterações em suas sociedades e seus respectivos territórios.

Primeiramente os universitários foram questionados se sentiam diferença entre a comida brasileira e a comida do país de origem, sendo que $85 \%$ afirmaram sentir diferença e $15 \%$ afirmam não sentir diferença. É o distanciamento entre o Eu e o Outro, através de algo tão íntimo como a alimentação. Sendo que as principais diferenças entre a comida brasileira e a dos países de origem elencadas pelos universitários foram: tipo de preparações, ingredientes e tempero diferentes, além de falta de pratos tradicionais e de variedade de produtos. $\mathrm{O}$ item produtos caros também foi mencionado. Além disso afirmaram que a comida do Brasil possui: excesso de gordura, menor consumo de farinha, menor consumo de frutas e vegetais, maior consumo de carne e consumo de grãos diariamente.

Pode-se estabelecer um diálogo com a nutricionista Rosa Wanda Diez Garcia, que ressalta que nas práticas alimentares estão incluídas: “[...] a identidade cultural, a condição social, a memória familiar expressa nos procedimentos relacionados à escolha e à preparação do alimento e ao seu consumo propriamente dito" (GARCIA, 2005, p.277). Portanto verificase a comida como identidade do local de origem, e/ou identidade étnica e o reforço da fronteira entre o Eu e Outro, entre a minha comida e a do Outro.

Questionou-se se eles costumavam trazer para o Brasil algum alimento típico de seu país, sendo que $61 \%$ responderam que sim, $21 \%$ não e $18 \%$ ainda não retornaram ao seu país desde que chegaram ao Brasil. Vale ressaltar como dito anteriormente que $64 \%$ reside no Brasil 

e-ISSN 2016/Atual: 2525-7870 | e-ISSN 2015/2016: 2447-018X

entre 5 a 6 meses. As práticas, hábitos e/ou comportamentos alimentares envolvem além do ato de nutrir-se, todo o contexto sociocultural à mesa: o que, quando, onde, porque, a sequência dos pratos servidos, o tempo, o modo de preparo, quem prepara, os acompanhamentos e os comensais. Estes são elementos que constituem a ritualização à mesa e dão significados a essa prática social. Neste viés, compreende-se que as memórias gustativas e/ou memórias alimentares não são aquelas ligadas necessariamente apenas ao sensorial, mas que perpassam os aspectos ligados à ritualização à mesa e as práticas alimentares, envolvendo não apenas aromas, sabores, sons, texturas, mas pessoas, lugares, acontecimentos, rituais de passagem, saberes, técnicas e práticas culturais. Portanto, ressalta-se o alimento como item simbólico e carregado de significados (STEFANUTTI, 2015).

Neste sentido, quando se questionou as dificuldades encontradas pelos estudantes em fazer compras nos supermercados brasileiros obteve-se as seguintes respostas: não encontrar ingredientes de seu país, seguido de, não compreender rótulos, não conhecer as verduras, falta de dinheiro e inflação, e alguns não responderam à pergunta. A Figura 4 apresenta as porcentagens de respostas para as dificuldades encontradas ao fazer compras, sendo que a mais citada foi "não encontrar ingredientes de seu país de origem".

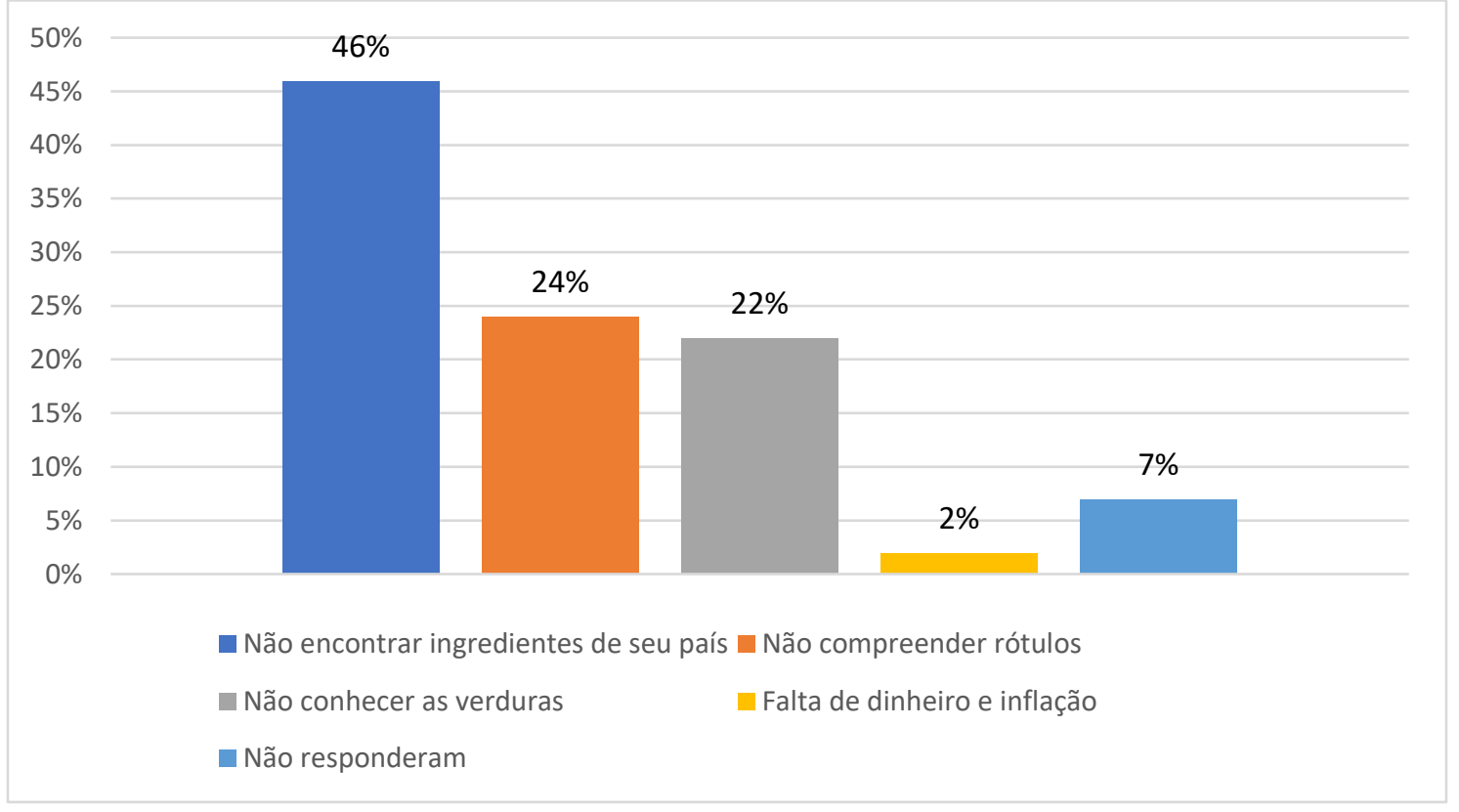

Figura 4 - Porcentagens de respostas para as dificuldades encontradas ao fazer compras. Fonte: do autor

Estes dados corroboram a necessidade de os estudantes aprimorarem seus conhecimentos sobre ingredientes e produtos brasileiros, para que possam fazer substituições de ingredientes não somente para elaboração de pratos regionais de sua cultura como também para melhor gerenciamento de seus recursos, já que a questão financeira também foi apontada como empecilho para a melhoria na alimentação. 


\section{Considerações Finais}

Com a pergunta norteadora de como poderiam melhorar sua alimentação, os universitários estrangeiros da UNILA relataram sete pontos que foram sendo discutidos ao longo do texto e que os fizeram refletir sobre seus comportamentos alimentares, sendo estes: possuir mais tempo, possuir mais dinheiro, aprender a cozinhar melhor, comer frutas e verduras, ter horário de alimentação adequada, ter conhecimento de uma dieta equilibrada e aprender a fazer compras.

O item tempo foi uma discussão importante que gerou debates sobre os horários de estudos, quantidade de refeições e horário de alimentação adequada, além de reflexões sobre a redefinição do significado da refeição. A parte econômica também foi citada, gerando discussões sobre recursos financeiros e escolhas alimentares. O item comer frutas e verduras, desencadeou debates sobre os principais alimentos que compõem a dieta alimentar, sendo que a maior parte deles está na categoria dos alimentos in natura ou minimamente processado.

Dos itens mencionados, três tem relação direta com o conhecimento culinário e nutricional, sendo estes: aprender a cozinhar melhor e a fazer compras e possuir conhecimento de uma dieta equilibrada. Portanto, levantou-se uma importante discussão da valorização do ato de cozinhar e da relevância de ser incluída no currículo escolar, matérias voltadas a educação alimentar e nutricional, abrangendo temas como a importância da alimentação na sociedade, princípios básicos de nutrição, alimentos funcionais, alimentos orgânicos, obtenção de alimentos, biodisponibilidade, preços e fornecedores. Pode-se ressaltar que a educação alimentar e nutricional poderia proporcionar maior qualidade de vida a esses universitários.

Ainda foi possível realizar discussões sobre adaptações alimentares e seus desafios, reforçando o alimento como um elemento simbólico e cultural, capaz de ativar memórias gustativas ligadas não apenas ao sabor, mas aos saberes, lugares e pessoas, assim como ressaltar identidade. Espera-se que esta pesquisa possa contribuir para outras análises, promovendo uma aproximação entre nutrição e ciências sociais, entendendo a alimentação como um fenômeno social a ser analisado de forma interdisciplinar.

\section{Referências}

BRASIL. Lei 12.189 de 12 de janeiro de 2010. Dispõe sobre a criação da Universidade da Integração Latino-Americana - UNILA e dá outras providências. Disponível em: <http://www.planalto.gov.br/ccivil_03/_ato2007-2010/2010/lei/L12189.htm> Acesso em: 05 abr. 2017. 
BRASIL. Ministério da Saúde. Secretaria de Atenção à Saúde. Departamento de Atenção Básica. Guia alimentar para a população brasileira. 2. ed. Brasília: Ministério da Saúde, 2014.

GARCIA, Rosa Wanda Diez. Alimentação e saúde nas representações e práticas alimentares do comensal urbano. In: CANESQUI, Ana Maria; GARCIA, Rosa Wanda Diez. (Org.). Antropologia e nutrição: um diálogo possível. Rio de Janeiro: Editora FIOCRUZ, 2005. p. 211-225.

GIARD, Luce. Artes de nutrir. In: CERTEAU, Michel de; GIARD, Luce; MAYOL, Pierre. A invenção do cotidiano: 2. Morar, cozinhar. Tradução: Ephraim Ferreira Alves e Lúcia Endlich Orth. 7 ed. Petrópolis, RJ: Vozes, 2008. p. 211-332.

GUIMARÃES, Camila Aude. A feira livre na celebração da cultura popular. 2010.

Disponível em: <http://200.144.182.130/celacc/sites/default/files/media/tcc/140-481-1-

PB.pdf >. Acesso em: 18 abr. 2017.

MINISTÉRIO DA EDUCAÇÃO. Censo da Educação Superior 2014. Notas Estatísticas. Disponível em:

<http://download.inep.gov.br/educacao_superior/censo_superior/documentos/2015/notas_sob re_o_censo_da_educacao_superior_2014.pdf>. Acesso em: 08 jun. 2017.

ORTIZ, Renato. Mundialização e Cultura. São Paulo: Brasiliense, 2003.

POLLAN, Michael. Cozinhar: Uma História Natural da Transformação. Tradução: Cláudio Figueiredo. Rio de Janeiro: Intrínseca, 2014.

SICHIERI, Rosely; COITINHO, Denise C.; MONTEIRO, Josefina B.; COUTINHO, Walmir F.. Recomendações de alimentação e nutrição saudável para a população brasileira. Arquivos Brasileiros de Endocrinologia \& Metabologia. 2000, vol.44, n.3, pp.227-232. Disponível em: <http://www.scielo.br/scielo.php?script=sci_arttext\&pid=S0004$27302000000300007>$. Acesso em: 13 jun. 2017.

STEFANUTTI, Paola. Do couvert ao café: pescadores, memórias e comidas. Foz do Iguaçu, Universidade Estadual do Oeste do Paraná, 2015. 174 p. Dissertação, mestrado em Sociedade, Cultura e Fronteiras, Universidade do Oeste do Paraná, Foz do Iguaçu, PR, 2015.

UNILA. Universidade da Integração Latino-Americana. A vocação da UNILA. Disponível em: <https://www.unila.edu.br/conteudo/voca\%C3\%A7\%C3\%A3o-da-unila> Acesso em: 20 abr. 2017.

UNILA. Universidade da Integração Latino-Americana. Disponível em: UNILA em Números. <https://www.unila.edu.br/sites/default/files/files/unila-em-numeros.pdf>. Acesso em: 26 abr. 2017. 